\title{
Substantiation of a Physical Model of Electromagnetic Field Interaction with a Food Product of an Arbitrary \\ Form
}

\author{
Potapov V.0., Mykhailov V.M., Mykhailova S.V., Borisova A.0.
}

\section{KEY WORDS}

Physical model, electromagnetic field, internal heat source, dielectric properties.

\begin{abstract}
Physical model of electromagnetic field interaction with a food product of an arbitrary form placed into a cavity super-high frequency chamber is substantiated. Physically correct equations for engineering analysis of electromagnetic field strength and density of the internal heat sources during microwave treatment of food products of an arbitrary form are received.
\end{abstract}

\section{Introduction (Heading 1)}

Use of microwave technologies is one of the effective methods of getting concentrated and dried food products [1, 2]. The speed of food products heating, SHFconcentration and SHF-drying largely depends on frequency and strength of electromagnetic field according to the product's volume, its geometrical dimensions and dielectric permeability. To ensure effective work of SHF-generator in order to receive high quality product it is necessary to fix rational power levels with the account of changes in the electromagnetic field strength depending on the surface area of the product and its properties that specifies the depth of the electromagnetic field penetration, as well as the rate of heating and moisture transfer.

Specific heat power released from the product during SHF-heating depends, on one side from electric parameters of a field (current frequency and the square of voltage), on the other - on dielectric parameters of the product (the angle of dielectric losses and relative dielectric permeability), and is determined by the well-known formula [3]

$\omega=2 \pi f \varepsilon_{0} \varepsilon \operatorname{tg} \delta E^{2}$

where: $\varepsilon_{0}$ is an electric constant $\left(\varepsilon_{0}=8,85 \cdot 10^{-12} \mathrm{~F} / \mathrm{m}\right)$; $f$ is the frequency of electromagnetic oscillations, $\mathrm{Hz}$; $\varepsilon$ is dielectric permeability of the environment; $\operatorname{tg} \delta$ is tangent of the angle of losses; $E$ is electric field strength in the environment, $\mathrm{V} / \mathrm{m}$.

In practice, use of this formula collides with the necessity of solving electro-dynamic task concerning the determination of electromagnetic field inside the product. In some simplest cases such task can be solved, e.g., for the plate symmetrically placed in a single-mode resonating SHF-chamber [4]. But such decision is a rough approximation to real conditions of treatment in the most wide-spread types of SHF-devices - multimode resonating SHF-chambers, because the design of such chambers presupposes excitation of multimode electromagnetic fluctuations for the equalization of the appearing maximums or minimums of electromagnetic field strength according 
to the volume of a SHF-chamber. At the same time, division of the resulting field strength depends on dielectric properties of the product, its geometry and placement in a SHF-chamber. Therefore, taking the above-stated into account, it is impossible to determine $\mathrm{E}$ in formula (1). There are some approximate methods of calculating density of the internal heat sources, among which the simplest and the most popular is the formula [3]

$$
\omega=\frac{P}{V}
$$

where: $\mathrm{P}$ is the power of SHF-generator, $\mathrm{W} ; \mathrm{V}$ is a product's volume, $\mathrm{m}^{3}$.

During the calculation of $\omega$ in most cases this formula has a considerable error because it doesn't account dielectric properties of a product.

Different is the approach to the use of the equation (1) with the empiric dependence for the square of electromagnetic field strength $E^{2}$ inside the product. Thus, in work [5] it is suggested to use the method of steady regime for the determination of dielectric and thermal-physical characteristics according to the law of internal heat sources distribution. This method suggests finding physical characteristics of a product by the kinetics of SHFheating of a product. In this case it is necessary to carry out the corresponding experiment in order to determine coefficients of the corresponding empiric dependence for $E^{2}$.

Somewhat simpler methods are proposed in the work [6]. Based on the experiments on the study of SHF-heating speed for the bodies of different geometrical shape, the following formula is proposed for an average density of the internal heat sources by the body's volume $\mathrm{V}$

$$
\omega=\omega_{0} \exp \left(-\frac{V}{V_{0}}\right)^{n}
$$

where: $\omega_{0}, V_{0}, n$ are determined by the experimental dependence of the product's heating speed on its volume.

This formula quite correctly describes experimental data but contains unknown coefficients, which should each time be determined during the experiment.

\section{Problem Definition in General}

According to the presented information, an important problem of using microwave treatment is a correct engineering calculation of technological regimes of the processes of heating, concentration, and drying. Kinetics of these processes is primarily determined by two related factors - electromagnetic field strength and density of internal heat sources, which appear due to the polarization in imperfect dielectrics, which most of food products are referred to [3]. At the same time, there are no correct equations allowing conduct engineering calculations helping to determine strength of electromagnetic field and density of internal heat sources during the microwave treatment of food products of an arbitrary form.

The goal of the research is to substantiate physical model of electromagnetic field interaction with the product of an arbitrary form placed in resonating SHF-chamber, and development of physically correct equations for engineering calculations of electromagnetic field strength and density of internal heat sources during the microwave treatment of food products of an arbitrary form.

The main tasks are to improve methods of the determination of electromagnetic field strength for the solution of practical tasks of SHF-heating of semi-finished food products, and formulation of mathematical model of internal heat sources power.

The goal of the research is to substantiate physical model of electromagnetic field interaction with the product of an arbitrary form placed in resonating SHF-chamber, and development of physically correct equations for engineering calculations of electromagnetic field strength and density of internal heat sources during the microwave treatment of food products of an arbitrary form.

The main tasks are to improve methods of the determination of electromagnetic field strength for the solution of practical tasks of SHF-heating of semi-finished food products, and formulation of mathematical model of internal heat sources power.

\section{Presentation of the Material}

At the first stage of the investigation that is connected with the improvement of the methods of determination of electromagnetic field strength, which is generated in a resonator SHF-chamber, and power of SHF-generator. We may use wellknown electro-dynamic equations presented in [7, 8]. 
The density of electromagnetic field energy $\omega \omega_{\text {, }}$ saved in a unit of the volume of the environment, is determined by the formula

$$
\omega=\varepsilon_{0} \varepsilon E^{2}
$$

Power density $\mathrm{Pd}\left(\mathrm{W} / \mathrm{m}^{2}\right)$ transferred by the electromagnetic wave in the environment is determined by the formula

$$
P d=\nu \omega=\nu \varepsilon \varepsilon_{0} E^{2}
$$

where: $\nu=\frac{c}{\sqrt{\varepsilon \mu}}$ is the light velocity in the environment, $\mathrm{m} / \mathrm{sec}$; $\mathrm{c}$ is the light velocity in the vacuum $\left(c=\frac{1}{\sqrt{\varepsilon_{0} \mu_{0}}}\right), \mu_{0}$ is the magnetic constant $\left(\mu_{0}=4 \pi \cdot 10^{-7}\right.$ $\mathrm{H} / \mathrm{m}) ; \mu$ is the magnetic permeability of the environment.

In a working volume of SHF-chamber electromagnetic wave is transferred practically with the light velocity in the vacuum because dielectric and magnetic permeability equals $1\left(\varepsilon^{\prime}=\mu=1\right)$. That is why power density (5) transferred from SHF-generator to the product equals

$$
P d=c \varepsilon_{0} E_{0}^{2}
$$

where: $E_{0}$ is an electrical field strength in a SHFchamber, $V / m$.

If load of resonator SHF-chamber is optimal, i.e. correlated by the volume of the product and resonator (otherwise efficiency of the resonator is small and SHF-generator can break down), power density of electromagnetic wave on the line productfree volume of SHF-chamber can be determined as follows

$$
P d=\frac{P}{S}
$$

where: $\mathrm{P}$ is the power of SHF-generator, $\mathrm{W} ; \mathrm{S}$ is the surface area of the product, $\mathrm{m}^{2}$.

It is possible to determine electromagnetic field strength on the surface of the product equalizing right parts of (5) and (6)

$$
E_{0}=\sqrt{\frac{P}{\varepsilon_{0} c S}}
$$

The next step is to determine electromagnetic field strength, which appears in the very product because it differs from the intensity on the line product-environment of SHF-chamber due to dependence of the dissemination speed of electromagnetic wave on dielectric characteristics of the environments.
Under conditions of optimal loading of SHF-resonator all energy of electromagnetic wave is assimilated by the product, i.e. power density Pd of the electromagnetic wave doesn't change on the line product - SHF-chamber. On the grounds of (5) and (6) it is possible to write down

$$
\nu \varepsilon \varepsilon_{0} E_{V 0}^{2}=c \varepsilon_{0} E_{0}^{2}
$$

Hence, with the account of the expression for the light velocity in the environment, we get

$E_{V 0}^{2}=\frac{E_{0}^{2}}{\sqrt{\varepsilon}}$

With the account of the expression (8) we get

$E_{V 0}=\sqrt{\frac{P}{\varepsilon_{0} \sqrt{\varepsilon} c S}}$

So, formula (11) takes into consideration correlation between the power of SHF-generator, internal electromagnetic field in a food product and the surface of its area.

For the calculation of changes in the electromagnetic field strength by the depth of the product $E_{\Delta}$, a well-known formula can be used:

$E_{\Delta}=E \cdot e^{-\alpha \Delta}$

where: $a$ is the coefficient of the wave attenuation $\alpha=\frac{1}{\delta} ; \Delta$ is the distance from the surface of the product to the point where the electromagnetic field strength is determined, $\mathrm{m} ; \delta=\frac{c}{\pi f \sqrt{\varepsilon^{\prime}} \operatorname{tg} \delta}$ is the depth of electromagnetic field penetration into the product, $\mathrm{m}$.

The coefficient of the wave attenuation $\alpha$ is an important factor in formula (12). Its meaning depends on the depth of the electromagnetic field permeability $\delta$, which, in its turn, depends on the complex of dielectric properties of a semi-finished food product and their changes in the process of heating and dehydration.

Therefore, power density, heating rate and moisture transfer are under the influence of the electromagnetic field strength by the volume of a semifinished food product together with the complex of its dielectric, and heat- and mass-exchanging characteristics. It becomes possible to determine electromagnetic field strength produced by the 
SHF-generator on the surface and internal layers of a food product during the solution of practical problems concerning SHF-heating of semi-finished food products with the predetermined thermal physical and dielectric properties on the basis of the proposed methods.

The received experimental data concerning the changes of dielectric properties of the mixture from crushed roots of spicy vegetables (parsley, parsnip, celery) and the depth of electromagnetic field penetration $[9,10]$ were used for checking the possibility of adapting the proposed methods for further solution of the problems of heat exchange in a working chamber of SHF- apparatus. The calculations allowed receive data for the construction of electromagnetic field strength dependencies on

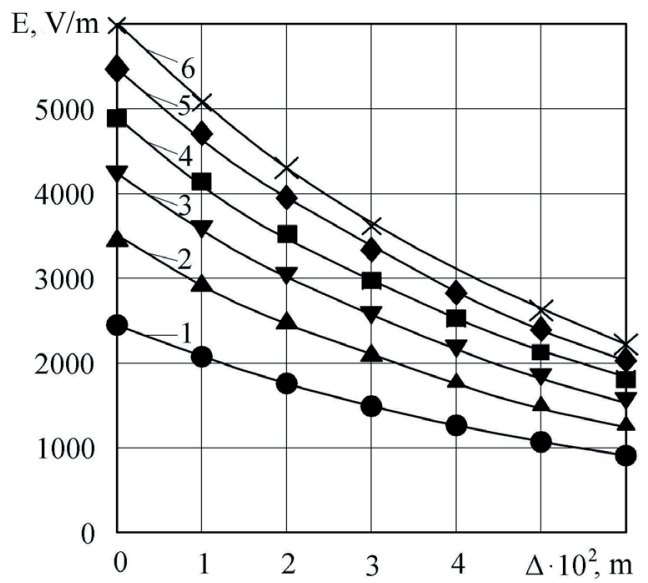

SHF-generator power and surface of the product on both surface and internal layers of the mixture under research (Fig. 1).

The presented dependencies demonstrate that electromagnetic field strength increases 2,45 times in all cases with the increase of SHF-generator power in the diapason from $500 \mathrm{~W}$ to $3000 \mathrm{~W}$. At the same time it is worth noting that increase of strength (intensity) alongside with the raise of power is uneven. Thus, when the power changes from $500 \mathrm{~W}$ to $1000 \mathrm{~W}$, electromagnetic field strength increases 1,41 times, from $1000 \mathrm{~W}$ to 1500 $\mathrm{W}-1,22$ times, from $1500 \mathrm{~W}$ to $2000 \mathrm{~W}-1,15$ times, from $2000 \mathrm{~W}$ to $2500 \mathrm{~W}-1,11$ times, and from 2500 $W$ to $3000 \mathrm{~W}-1,09$ times.

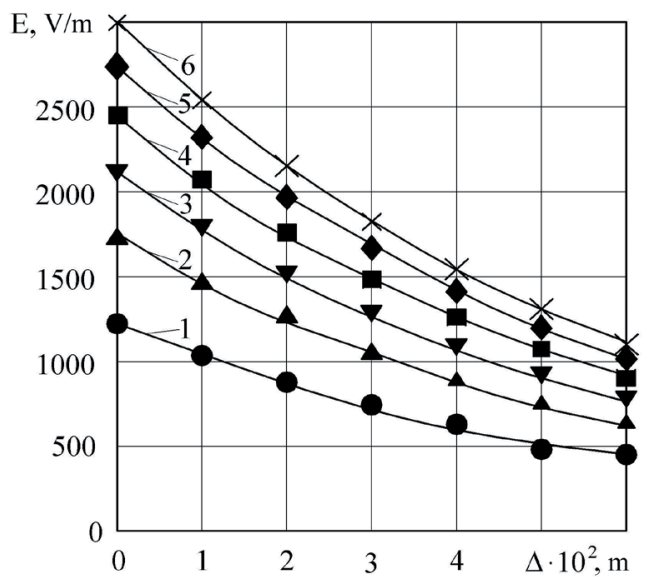

Fig. 1: Electromagnetic field strength depending on the layer thickness $(\triangle)$ and SHF-power $(P)$ for the mixture from crushed roots of spicy vegetables: $1-500 W ; 2-1000 W ; 3-1500 W ; 4-2000 W ; 5-2500 W ; 6-3000 W$, for the area of the product surface: $a-50 \mathrm{~cm}^{2} ; 6-200 \mathrm{~cm}^{2}$

Change of the electromagnetic field strength is proportional to the area of the product surface. Thus, with the area $50 \mathrm{~cm}^{2}$ electromagnetic field strength is within the limits of $2450 \ldots 5990 \mathrm{~V} / \mathrm{m}$, at the area $200 \mathrm{~cm}^{2}$ - within $1220 \ldots 3000 \mathrm{~V} / \mathrm{m}$. permeability of electromagnetic energy inside the product is followed by its reduction according to exponential dependence. Under the mentioned ranges of intensity on the surface of the product, at the depth of $0,06 \mathrm{~m}$ its value is within the limits $910 \ldots 2220 \mathrm{~V} / \mathrm{m}, 450 \ldots 1100 \mathrm{~V} / \mathrm{m}$ respectively.

Hence, by the example of calculations made for the mixtures from crushed roots of spicy vegetables it was determined that electromagnetic field strength can be regulated through the change of SHF-generator capacity and surface area of the product, which determine intensity of the interior heat sources, and, respectively, intensity of thermal and mass-exchange processes in order to achieve the predetermined quality of a ready product.

The next step of the work is the formulation of mathematical model of the internal heat sources intensity. Modeling of the internal heat sources intensity was carried out with the account of the electromagnetic energy absorption effect in a product from the surface to its center (Fig. 2).

For this purpose let's note power balance for any internal layer of a product with the volume $\mathrm{d} V$ with the surface area Sv.

The symbol «-» points that intensity of internal electromagnetic field $E_{i}$ reduces due to its transformation to heat in the equation (13). 


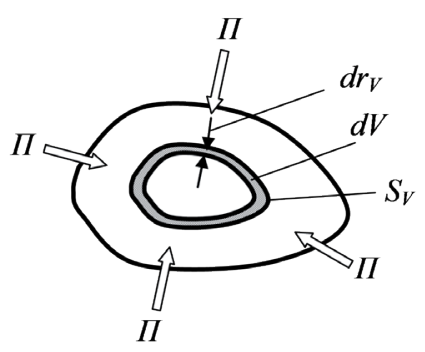

Fig. 2: Chart of calculation of power of internal sources of warmth

$$
\varpi d V=-S_{V} d \Pi
$$

On the basis of (1) and (5) with the account of light velocity in the environment we get

$$
2 \pi f \varepsilon_{0} \varepsilon \operatorname{tg} \delta E_{i}^{2} \cdot d V=-c \varepsilon_{0} \sqrt{\varepsilon} S_{V} \cdot d\left(E_{i}^{2}\right)
$$

With the account of the expression for the depth of SHF-energy penetration into dielectric $(\delta, \mathrm{M})[7]$

$$
\delta=\frac{c}{2 \pi f \varepsilon_{0} \sqrt{\varepsilon} \operatorname{tg} \delta}
$$

and on the basis (14) we receive the following differential equation

$$
\frac{d\left(E_{i}^{2}\right)}{E_{i}^{2}}=-\frac{1}{\delta} \frac{d V}{S_{V}}=-\frac{1}{\delta} d r_{V}
$$

where: $r v$ is current distance along the normal from the surface to the internal layer of a product $d V$.

The solution (16) according to boundary condition $\left.E_{i}\right|_{w=0}=E_{i 0}$ looks like (17) and describes the division of electromagnetic field strength by the internal volume of the product

$$
E_{i}^{2}=E_{i 0}^{2} e^{-\frac{N}{\delta}}
$$

Substituting (17) into (1) with the account of (11) and (15) we receive a calculation formula to determine density of heat sources by the internal volume of the product during its SHF-treatment

$\omega\left(r_{V}\right)=\frac{P}{\delta S} e^{-\frac{N}{\delta}}$.

The received formula coincides with the wellknown formula (19) for the calculation of the internal heat sources density that is usually presented like [1] $\omega(x)=\omega_{0} e^{-\frac{x}{\delta}}$

but unlike (19) formula (18) contains the power level for the internal heat sources on the surface of the product $\omega_{0}=P /(\delta S)$, and this formula can be universally applied because it was received for an arbitrary form of the product, characteristic dimension of which is volume-to-surface rate $\left(0 \leq r_{v} \leq \mathrm{V} / \mathrm{s}\right)$.

Reception of the calculation formula for an average intensity of the internal heat sources by the volume product is a very important practical matter because it is most frequently used in engineering calculations.

On the grounds of (18) for an average specific power of the internal heat sources we'll determine through integrating

$\omega=\frac{P}{\delta S} \frac{1}{R_{V}} \int_{0}^{R_{V}} e^{-\frac{n_{V}}{\delta}} d r_{V}=\frac{P}{V}\left(1-e^{-\frac{R_{V}}{\delta}}\right)$

where: $R_{V}=V / S$ is volume-to-surface rate, $\mathrm{m}$.

If the received formula (20) is compared with the well-known approximation for the density of the internal heat sources (2), it coincides when $R_{v} / \delta » 1$, i.e. only when the product volume is large. It is known that for the provision of SHF-heating evenness, dimensions of the product mustn't exceed SHF-energy penetration depth. That is why in these cases formula (2) may give error in calculations.

Experimental data from [6] were analyzed in order to check adequacy of the received equation (20). The power of the internal heat sources was determined in the experiments by the water heating rate in the containers of different geometrical shapes. They were placed in a microwave cooker with 15 I volume and power $500 \mathrm{~W}$ (Fig. 3). Points on a curve denote experimental data, solid graph marks calculation by the formula (20) for each type of the container. Experimental checkout proved physical adequacy of the received equation.

Therefore, calculation formula for the determination of an average by the product's volume specific power of the internal heat sources during its SHFtreatment was received by means of mathematical modeling of the internal heat sources power with the account of the effect of electromagnetic energy absorption in the product from the surface to its center. The formula has universal application for the arbitrary form of the product, characteristic di- 
mension of which is volume-to-surface rate.

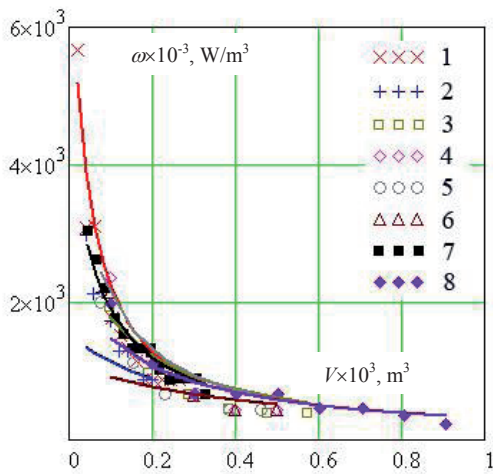

Fig. 3: Comparison of experimental and calculated data of internal heat sources density during SHF-heating of water in the containers of various forms: 1 -cylinder $D=57 \mathrm{~mm} \mathrm{H}=10 \ldots 80 \mathrm{~mm}$; 2-parallelepiped $170 \times 75 \mathrm{~mm} \quad H=3 \ldots 10 \mathrm{~mm}$; 3-cylinder $D=90 \mathrm{~mm}$ $H=15 \ldots 90 \mathrm{~mm}$; 4-cylinder $\mathrm{D}=70 \mathrm{~mm} \quad H=20 \ldots 120 \mathrm{~mm}$; 6-cylinder $D=120 \mathrm{~mm} \quad H=5 \ldots 28 \mathrm{~mm} ; 7$-parallelepiped $97 \times 45 \mathrm{~mm} H=10 \ldots$ $75 \mathrm{~mm} ; 8$-parallelepiped $120 \times 70 \mathrm{~mm} \mathrm{H}=12 \ldots 108 \mathrm{~mm}$.

\section{Conclusions}

1. It is proved that for the provision of effective work of SHF-generator it is necessary to specify rational power level with the account of changes in electromagnetic field strength depending on the surface of the product and its properties, which determine electromagnetic field penetration depth, heating rate and moisture transfer.

2. The method of determining electromagnetic field strength on the surface and by the depth of the product that takes into account interrelation between the SHF-generator power, internal electromagnetic field in a food product and its surface is improved for the solution of practical tasks on heat and mass-exchange, connected with SHFheating and SHF-concentration of food products. The relationship of the subsidence ratio with the depth of its penetration, a complex of dielectric properties and their changes in the process of heating and dehydration is demonstrated.

3. The formula for engineering calculations of internal heat sources density during microwave treatment of food products, which take into account SHF-generator power, an arbitrary geometry of the product (the volume and area of the surface) and electromagnetic field penetration depth, was received on the grounds of fundamental equations of the theory of electrodynamics.

\section{References}

[1] Pat. 45999 Ukraina, MPK A23L 1/01. Sposib prigotuvannya pasti z pryano-aromatischnih ovochiv / Cherevko 0. I., Efremov U. I., Mihaylov V. M., Mihaylova S. B., Volohin V. P., Golub R. V.; zayavnik i patentovlasnik HDUHT. - № u200903539; zayavl. 13.04.2009; opubl. 10.12.2009, Bul. № 23.

[2] Pat. 58158 Ukraina, MPK A23L 1/01. Sposib prigotuvannya porohkopodibnogo napivfabrikatu na osnovi pryanih ovoschiv / Cherevko 0. I., Efremov U. I., Mihaylov V. M., Mihaylova S. B., Kostrova K. V.; zayavnik i patentovlasnik HDUHT. - № u201008082; zayavl. 29.06.2010; opubl. 11.04.2011, Bulл. № 7.

[3] Rogov I.A. Elektrofizisheskie metodi obrabotki pischevih produktov. - M. Agropromizdat, 1988. - $272 \mathrm{p}$.

[4] Kalinin L. G. Primenenie metoda regulyarnogo regima dlya opredeleniya elektroteplofizicheskih harakteristik dispersnih sistem / Naukovi praci ONAHT. - Odesa: 2010. - № 37. - s. 170-173.

[5] Potapov V.0., Curkan M.M. Doslidgennya umov rivnomirnogo nagrivannya harchovoi sirovini u funkzionaknii mistkosti NVH-suharki.

[6] Pogogih N. I., Curkan N. M., Gricenko 0. Ya. Opredelenie napryagennosti SVH-polya po temperature nagreva modelnogo tela / Naukovi prazi ONAHT. Odesa, 2011, № 39, T2. S. $22-25$.

[7] Netuhil A. V. Visokochastotniy nagrev dielektrikov I poluprovodnikov / A.V. Netuhil I dr. - M. - L.: Gosenergoizdat, 1956. 480 s.

[8] Civuhin D.V. Obschiy kurs fiziki. - Izd. 4-e, stereotipnoe. - M.: Fizmatlit; Izd-vo MFTI, 2004. - T. III. Elektrishestvo. - 656 p.

[9] Mihaylov V. M. Dielektrichni haracteristiki sumihei z pryanih ovochiv / V. M. Mihaylov V. O. Potapov, Ya. I. Efremov, S. V. Mihaylova // Obladnannya ta tehnologii harchovih virobniztv : temat. zb. nauk. pr. - 2012 r. - . 29, t. 2. - S. 260.

[10] PotapovV.0., Mihaylova S.V. Viznaschennya glubini pronicnennya elektromagnitnogo polya ta racionalnoi tovhini haru podribnenih pryanih ovoschiv dlya SHF -obrobki [Text] // Suschasni napryamki tehnologii ta mehanizacii procesiv pererobnih i harschovih virobnictv. - Kharkiv: (HIMESH), 2012. -V-131. - p.80-87. 